\title{
The microtubule inhibiting agent epothilone $B$ antagonizes glioma cell motility associated with reorganization of the actin-binding protein $\alpha$-actinin 4
}

\author{
WHITNEY I. HENRY, JUWEN DUBOIS and QUINCY A. QUICK \\ Department of Biological Sciences, Grambling State University, Central and Main, Grambling, LA 71245, USA
}

Received November 2, 2010; Accepted December 23, 2010

DOI: $10.3892 /$ or.2011.1145

\begin{abstract}
Invasion of normal brain tissue by brain tumor cells is a major contributing factor to the recurrence and resistance of clinically diagnosed glioblastomas to therapy (surgery, chemotherapy, radiation). Here, we have assessed the efficacy of the microtubule inhibiting agent epothilone B on glioblastoma cell motility, a prerequisite cellular program of invasive glioblastomas. Using cell migration assays and immunofluorescence techniques we demonstrated that epothilone B abrogated glioblastoma cell motility as a consequence of $\alpha$-actinin 4 redistristrubiton and the breakdown of cellular structures (leading edge, stress fibers) it is associated with during cell migration. Evaluation of the microtubule actin cross linking factor in glioblastoma cells also revealed epothilone $B$ invoked changes in this cytoskeleton cross linking protein, resembling $\alpha$-actinin 4 changes in response to epothilone $\mathrm{B}$. We have demonstrated in this study that epothilone B antagonizes glioblastoma cell motility due to the disruption of cytoskeleton binding proteins that aide in preserving the structural organization of the cytoskeleton filamentous network. Furthermore, we provide preclincial evidence that epothilone $\mathrm{B}$ effects on glioblastomas are not limited to the impairment of dividing tumors cells but that it also targets migratory and invasive glioblastoma cells, suggesting that this agent has potential clinical benefit due to its ability to target divergent cellular programs in the glioblastoma tumor mass.
\end{abstract}

\section{Introduction}

In the last thirty-five years primary malignant brain and central nervous system tumors have had an $\sim 25 \%$ relative

Correspondence to: Dr Quincy A. Quick, Department of Biological Sciences, Grambling State University, Central and Main, Grambling, LA 71245, USA

E-mail: quincyquick@ymail.com

Key words: $\alpha$-actinin 4, microtubule actin cross-linking factor, glioblastoma, epothilone B survival rate of five years post-diagnosis. This suggests that clinically used treatment protocols (i.e. surgery, radiation, chemotherapy) for central nervous system neoplasms are marginally effective in curing this disease. The refractoriness of primary brain tumors to conventional treatment modalities can be attributed in part to high rates of tumor recurrence, which occurs in greater than $95 \%$ of diagnosed cases (1), as a consequence of increased tumor cell motility and invasion of normal brain tissue. The ability of neoplastic cells to evade clinically used therapies and metastasize to different sites is due to the structure and function of cytoskeletal filamentous proteins (microtubules, intermediate filaments, actin filaments). To date the most widely used agents targeting a cytoskeletal protein during the clinical treatment of human cancers, particularly invasive gliomas, have been microtubule inhibiting agents (vincristine, colchicine, and taxol) (2-6). However, the clinical effectiveness of these compounds is limited due to harmful therapeutic consequences associated with clinical toxicities (i.e. CNS toxicity, nausea, and hematological toxicity). Additionally, microtubule inhibiting agents used for the clinical treatment of gliomas are known substrates for P-glycoprotein (P-gp), an energy dependent drug efflux transporter protein product that plays an intricate role in the cellular resistance of cancer cells to chemotherapeutic agents (7-9). These clinical caveats have made it necessary to investigate the utility of novel agents and approaches that target cytoskeletal proteins in gliomas and other human cancers that are involved in tumor cell invasion.

To this end a group of microtubule-stabilizing agents isolated from the myxobacterium Sorangium cellulosum, epothilones, which are not substrates for P-glycoprotein, are candidate therapeutic agents to overcome glioma cell resistance associated with normal brain tissue invasion. We assessed the utility of epothilone B to antagonize glioblastoma cell motility and its effects on cellular structures and proteins involved in this cellular process that precedes the invasion of normal brain tissue.

\section{Materials and methods}

Cell conditions and reagents. U373, LNZ, and U87 glioblastoma cells were purchased from the American Type Culture Collection (Manassas, VA, USA). All cell lines were 
maintained in Dulbecco's modified Eagle's medium-DMEM (Invitrogen, Carlsbad, CA, USA) containing 10\% fetal bovine serum (Invitrogen), $2 \mathrm{mM}$ L-glutamine (Invitrogen), $100 \mathrm{nM}$ MEM non-essential amino acids (Invitrogen), and penicillinstreptomycin (Invitrogen) at $37^{\circ} \mathrm{C}$ and $5 \% \mathrm{CO}_{2}$. Epothilone $\mathrm{B}$ was purchased from EMD-Calbiochem Biosciences (San Diego, CA, USA).

Crystal violet cell proliferation assay. Cells were plated in 24-well plates for $24 \mathrm{~h}$, treated with 1,10 , and $25 \mathrm{nM}$ epothilone B (Sigma-Aldrich, St. Louis, MO, USA). Vehicle controls were treated with DMSO and allowed to incubate for $48 \mathrm{~h}$. Next tissue culture medium was removed; the cell monolayer was fixed with $100 \%$ methanol for $5 \mathrm{~min}$ and stained with $0.5 \%$ crystal violet in $25 \%$ methanol for $10 \mathrm{~min}$. Cells were then washed three times 5 min each with distilled water to remove excess dye and allowed to dry overnight at room temperature. The incorporated dye was then solubilized in $0.1 \mathrm{M}$ sodium citrate (Sigma-Aldrich) in 50\% ethanol. Next, $100 \mu \mathrm{l}$ of treated and control samples were transferred to 96 -well plates and optical densities read at $540 \mathrm{~nm}$ using a Bio-Rad 680 microplate reader (Bio-Rad, Hercules, CA, USA).

Cell motility. Motility assays were conducted according to manufacturer's instructions (Cell Biolabs, Inc., San Diego, CA). A cell suspension containing $0.5-1.0 \times 10^{6}$ cells $/ \mathrm{ml}$ was prepared in serum free media with vehicle (DMSO) or $25 \mathrm{nM}$ epothilone B, while $500 \mu 1$ of media containing $10 \%$ fetal bovine serum was added to the lower chamber of the migration plate. Cell suspension (300 $\mu 1)$ containing vehicle or $25 \mathrm{nM}$ epothilone $\mathrm{B}$ was then added to the inside of each insert and allowed to incubate for $24 \mathrm{~h}$ at $37^{\circ} \mathrm{C}$ and $5 \% \mathrm{CO}_{2}$. Subsequently, non-migratory cells were removed from plate inserts (per manufacturer's instructions) and migratory cells were counterstained with cell stain solution (Cell Biolabs Inc.). Migratory cells were then counted with a Leica-DM 1000 light microscope.

Cell adhesion assay. Cell suspensions containing 0.1-1.0 $\times 10^{6}$ cells $/ \mathrm{ml}$ in serum free media containing vehicle (DMSO) or $25 \mathrm{nM}$ epothilone B, were plated on collagen IV adhesion plates (Cell Biolabs, Inc.) for $24 \mathrm{~h}$. Subsequently, vehicle and $25 \mathrm{nM}$ epothilone B was removed, cells were stained with cell stain solution (Cell Biolabs, Inc.) and solubilized with cell extraction solution (Cell Biolabs, Inc.). Optical Density measurements $(540 \mathrm{~nm})$ were then taken of cell extracts to quantitate adhesive properties of control and epothilone B treated cells.

Western blotting. Cells were plated in DMEM containing $10 \% \mathrm{FBS}$ for $24 \mathrm{~h}$, treated with $25 \mathrm{nM}$ epothilone B (EMD-Calbiochem) or vehicle, and allowed to incubate for 1 and $2 \mathrm{~h}$. Cells were then lysed in lysis buffer ( $\mathrm{pH}$ 6.8) containing $60 \mathrm{mM}$ Tris and 2\% SDS. Protein concentrations were determined using the Bradford Method. Subsequently, protein samples were electrophoresed in a $4-12 \%$ Tris- $\mathrm{HCl}$ polyacrylamide gel, transferred to nitrocellulose membranes and immunoblotted with antibodies against $\alpha$-actinin 4 (Novus Biologicals, Littleton, CO). Protein levels were detected using

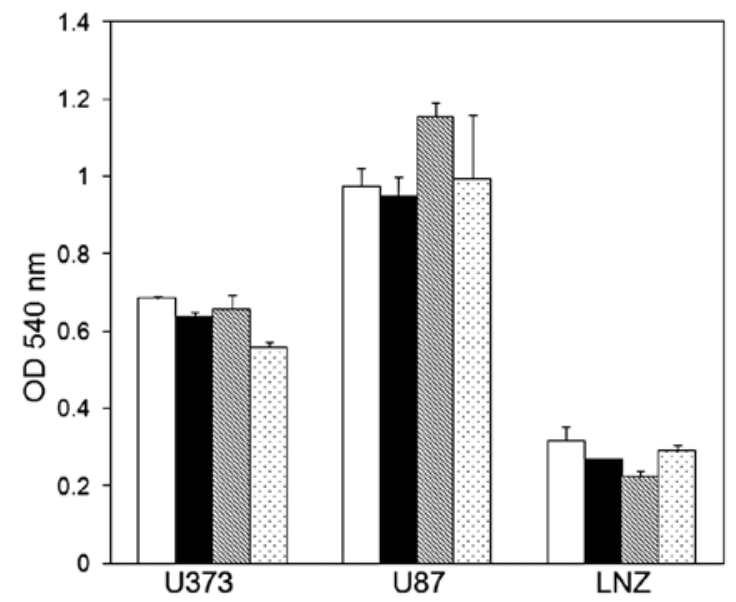

Figure 1. Dose response experiments of epothilone B treated glioblastoma cells. Vehicle treated control cells (solid white bars); $1 \mathrm{nM}$ epothilone B (solid black bars); $10 \mathrm{nM}$ epothilone B (hatched white bars); $25 \mathrm{nM}$ epothilone B (speckled black bars). Data shown are representative of three independent experiments (means $\pm \mathrm{SE}$ ) performed in duplicate showing similar results.

a horseradish peroxidase conjugated secondary antibody and a colorimetric detection system (Bio-Rad).

Immunofluorescence labeling. Cells were plated and allowed to attach for $24 \mathrm{~h}$. Cells were then treated with epothilone B $(25 \mathrm{nM})$ or vehicle (DMSO) for $24 \mathrm{~h}$, rinsed in PBS, and fixed in $4 \%$ paraformaldehyde for $5 \mathrm{~min}$ at room temperature. Next cells were rinsed with PBS post-fixation, permeabilized in 0.075\% Triton X-100/PBS for $5 \mathrm{~min}$, rinsed again with PBS, and blocked with $3.0 \%$ bovine serum albumin, $1.5 \%$ horse serum (Vector Labs, Burlingame, CA, USA) in PBS for $1 \mathrm{~h}$ at room temperature. Cells were next incubated overnight at $4^{\circ} \mathrm{C}$ with an antibody that detects either $\alpha$-actinin 4 (Novus Biologicals) or MACF (Santa Cruz Biotechnology). Samples were then rinsed three times with PBS, incubated with an Alexa 488 goat-anti-mouse conjugated secondary antibody (Molecular Probes, Invitrogen) for $1 \mathrm{~h}$ in the dark, rinsed again and examined with an Leica-DM 1000 fluorescent microscope.

\section{Results}

Epothilone B inhibits glioma cell motility. It is well established that microtubule inhibiting agents, such as epothilone B, induce positive anti-tumorigenic responses as a consequence of antagonizing mitotic cell cycle progression. However, here we assessed the utility of epothilone B to impede the motility of glioblastoma cells. Prior to cell motility experiments to examine the effects of epothilone B on glioblastoma cell motility, dose response studies were conducted with epothilone B (1-25 $\mathrm{nM}$ ) to select the highest concentration with minimal toxicity for subsequent motility assays. To this end dose response assessment of epothilone B (1-10 nM) from our previous study (10), where we demonstrated the ability of epothilone B to inhibit the reproductive capacity of glioblastoma cells, revealed that $10 \mathrm{nM}$ epothilone B the highest concentration examined for its toxic effects did not invoke an $\mathrm{LD}_{50}$ response on glioblastoma cells studied (10). 


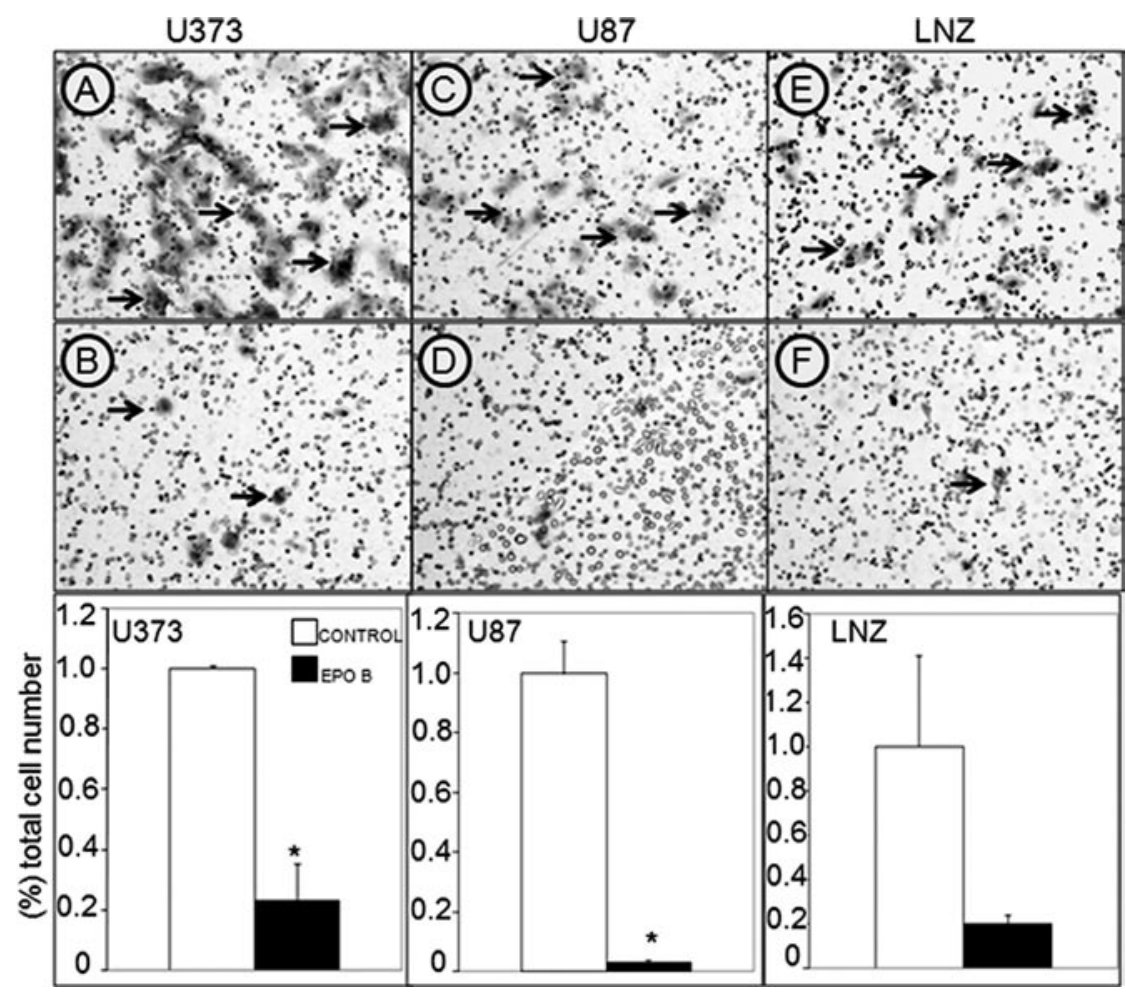

Figure 2. Effects of epothilone B on glioblastoma cell motility as determined by the boyden chamber assay. Vehicle (DMSO) treated cells (A, C and E) top panel; glioblastoma cells (U373, U87, LNZ) treated with $25 \mathrm{nM}$ epothilone B for $24 \mathrm{~h}$ (B, D and F) middle panel. Percent of total cell numbers counted (white bars, vehicle controls; black bars, $25 \mathrm{nM}$ epothilone B) bottom panel. Shown is an experiment representative of three independent experiments (means \pm SE) performed in duplicate that displayed similar results. "Statistically significant $\mathrm{p}<0.05$; arrows-stained cells. Total magnification, $\mathrm{x} 100$.

Consistent with our previous findings dose response data here also revealed the absence of an $\mathrm{LD}_{50}$ response and minimal toxicity to glioblastoma cells exposed to a 2.5 -fold increase in epothilone B concentration $(25 \mathrm{nM})$, although a $19 \pm 2 \%$ and $9 \pm 5 \%$ decrease in cell proliferation of U373 and LNZ cells was observed respectively, when compared to vehicle controls (Fig. 1).

Next we assessed the motility of glioblastoma cells treated with $25 \mathrm{nM}$ epothilone using the boyden chamber assay. We observed a significant decrease in the motility of glioblastoma cells treated with $25 \mathrm{nM}$ epothilone B (Fig. 2) as compared to vehicle controls in all cell lines (U373, U87, LNZ) tested, while $10 \mathrm{nM}$ epothilone B displayed no effect on cell motility (data not shown). The most pronounced effect of epothilone B on glioblastoma cell motility was seen in U87 cells which displayed $3 \pm 1 \%$ of cells were motile postepothilone B exposure, as compared to vehicle control treated cells (Fig. 2C and D), while $23 \pm 11 \%$ of U373 cells migrated after treatment with epothilone B as compared to controls. These data are consistent with previous studies that showed classic microtubule inhibiting agents (taxol, vincristine, vinblastine) also impede the motility of brain, ovarian, and colon cancer cells (11-14).

Cell motility involves a number of processes that include protrusion, attachment, and traction necessary for the migratory behavior of cells. In an effort to identify other cellular processes that might contribute to glioblastoma cell migration and might be inhibited by the anti-migratory effects of epothilone B on glioblastoma cells observed here, we also assessed the effects of epothilone B on glioblastoma cell adhesion. The data revealed a modest reduction in cell adhesion on epothilone B treated U373 and U87 cells (Fig. 3), while epothilone B appeared to have no effect on the adhesion of LNZ cells after the exposure.

Epothilone $B$ disrupts $\alpha$-actinin 4 in motile dependent subcellular structures. Cell migration depends a great deal on the filamentous cytoskeletal network that comprises subcellular structures and domains. As described above, epothilone $\mathrm{B}$ had a demonstrable effect on the motility of glioblastoma cells. We therefore examined the effects of epothilone B on subcellular regions that contribute to cell motility. Our observations revealed that gross morphological changes in cytoplasmic structures important for cell motility were induced in epothilone B treated glioblastoma cells in a dosedependent manner (Figs. 4 and 5). The most notable effects of epothilone B on cellular structures involved cell motility seen in U373 glioblastoma cells. Vehicle control treated U373 cells displayed an intact cytoplasm, leading edge, and trailing edge domain structures (Fig. 4A) that play intricate roles in cell motility. These structures were unaffected in U373 cells treated with $1 \mathrm{nM}$ epothilone B (Fig. 4B) but were drastically retracted in U373 cells treated with $10 \mathrm{nM}$ (Fig. 4C) and $25 \mathrm{nM}$ epothilone B (Fig. 4D), respectively. Consistent with U373 cells, epothilone B also affected the cytoplasmic integrity of U87 glioblastoma cells in a dose-dependent fashion. This was evidenced by the presence of cytoplasmic extensions in vehicle control and $1 \mathrm{nM}$ epothilone B treated U87 cells (Fig. 5A and B) that were dramatically reduced in U87 cells exposed to $25 \mathrm{nM}$ epothilone B (Fig. 5D) and to a lesser 


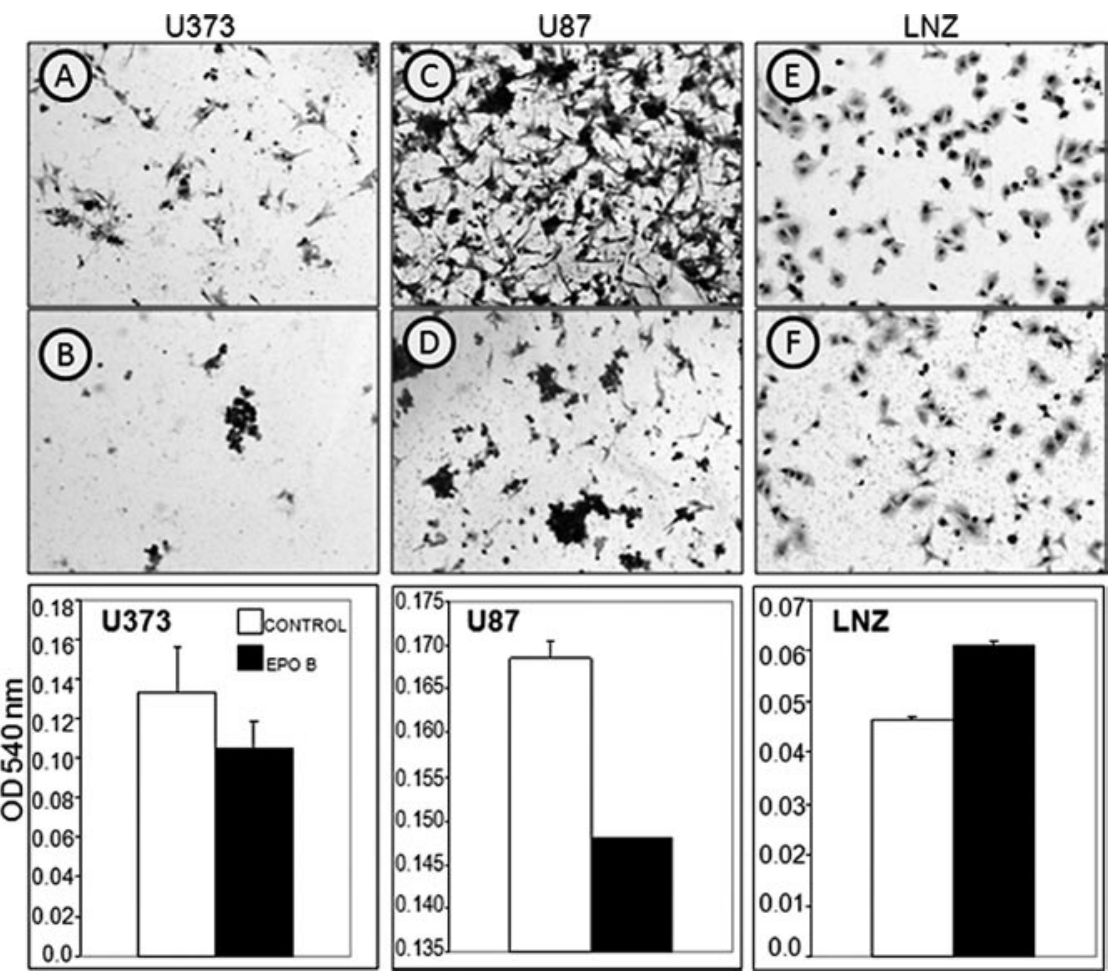

Figure 3. Assessment of glioblastoma cell adhesion in response to epothilone B exposure. Vehicle (DMSO) treated cells (A, C and E) top panel; glioblastoma cells treated with $25 \mathrm{nM}$ epothilone B for $24 \mathrm{~h}$ (B, D and F) middle panel. Absorbance taken at $540 \mathrm{~nm}$ (representative of total cell number) lower panel. Shown is an experiment representative (means \pm SE) of three independent experiments performed in duplicate that displayed similar results. Total magnification, $\mathrm{x} 100$.
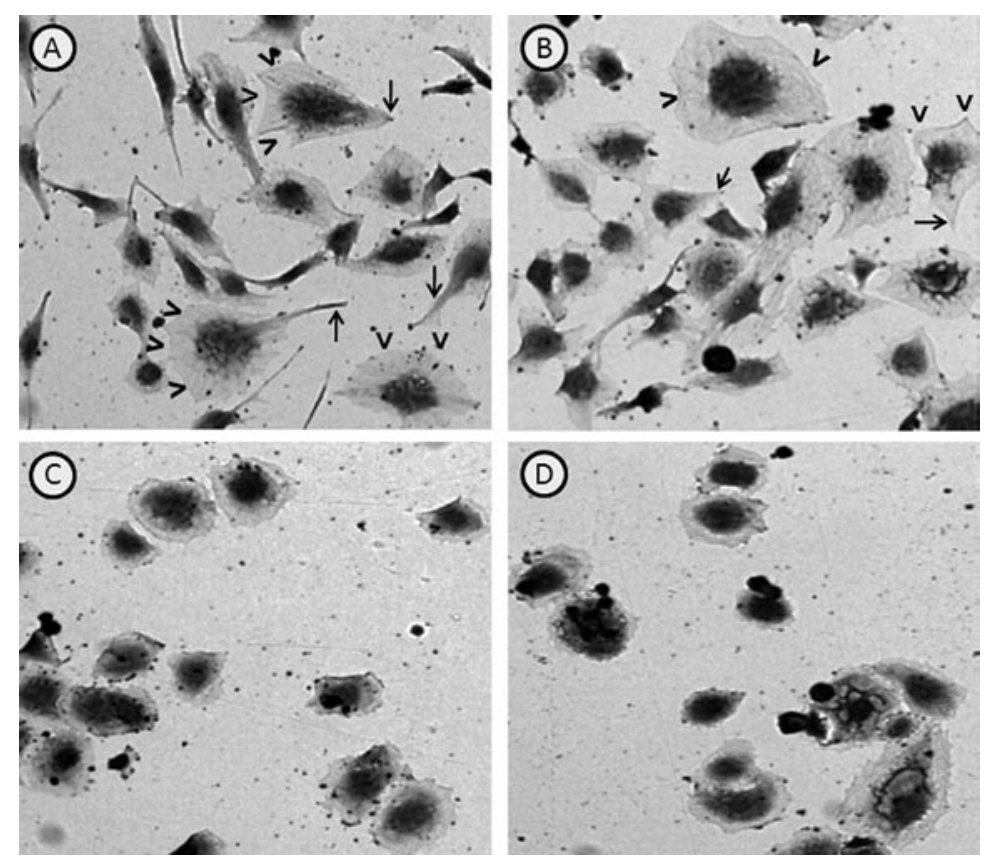

Figure 4. Dose dependent epothilone B induced changes of the leading edge and trailing edge in U373 glioblastoma cells. (A) Vehicle (DMSO) treated cells; (B) $1 \mathrm{nM}$ epothilone B; (C) $10 \mathrm{nM}$ epothilone B; (D) $25 \mathrm{nM}$ epothilone B. Arrow heads-leading edge, arrows-trailing edge. Displayed is a representative experiment of three independent experiments showing similar results. Original magnification, $\mathrm{x} 100$.

extent in U87 cells treated with $10 \mathrm{nM}$ epothilone B, which supports in part the lack of glioblastoma cell motility when treated with this concentration at least in U87 cells.

Gross morphological changes of glioblastoma cells induced by epothilone B described above demonstrated a disruption of the filamentous cytoskeletal network, most notably in the leading edge and trailing edge of U373 cells, domain structures known to be rich in actin and actin-binding proteins, such as $\alpha$-actinin $4(15,16)$. To better understand the mechanistic basis underlying observed morphological changes 


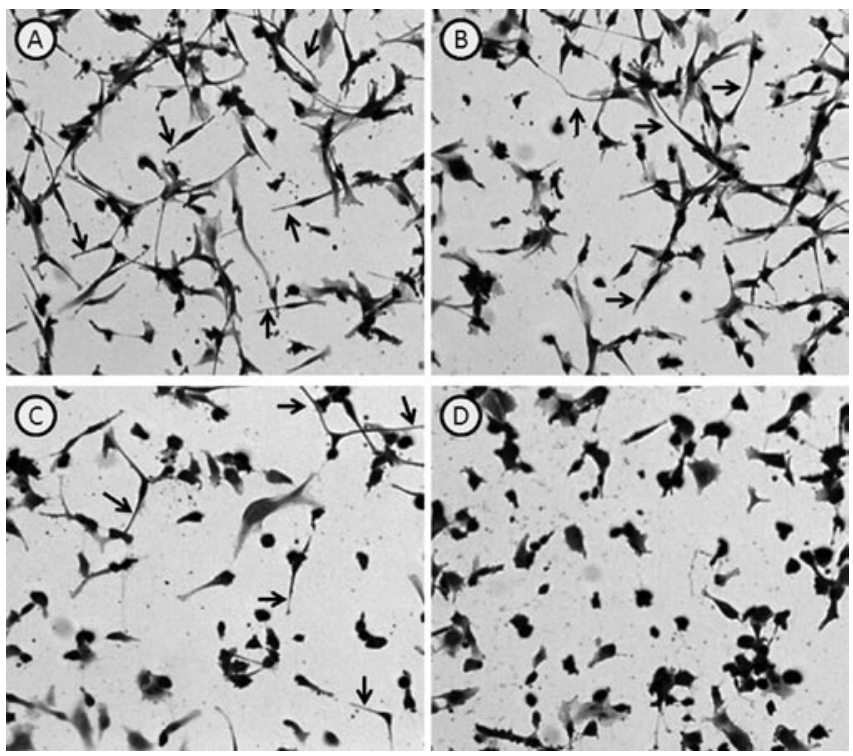

Figure 5. Dose-dependent epothilone B induced changes of cytoplasmic extensions in U87 glioblastoma cells. (A) Vehicle (DMSO) treated cells; (B) $1 \mathrm{nM}$ epothilone B; (C) $10 \mathrm{nM}$ epothilone B; (D) $25 \mathrm{nM}$ epothilone B. Arrows, cytoplasmic extenstions. Displayed is a representative experiment of three independent experiments showing similar results. Original magnification, $\mathrm{x} 100$.

of domain structures (leading edge, trailing edges, and stress fibers) in glioblastoma cells rich in actin and actin-binding proteins; we examined if epothilone B promoted changes in subcellular structures (leading edge, trailing edges, and stress fibers) that contain the actin-binding protein $\alpha$-actinin 4 , which functions to bundle actin microfilaments and has an established role in the motility of cancer cells (17-21). Immunofluorescence labeling studies with an antibody that detects $\alpha$-actinin 4 revealed a pronounced localization of this non-muscle $\alpha$-actinin isoform in the leading edge (U373, LNZ) and stress fibers (U373, U87, LNZ) of vehicle control treated cells (Fig. 6A, C and E). In contrast to vehicle control treated cells a perinuclear localization of $\alpha$-actinin 4 was observed in epothilone B treated glioblastoma cells (Fig. 6B, $\mathrm{D}$ and $\mathrm{F})$. These data parallel findings seen in endothelial (22) and breast cancer (23) cells, which also underwent filamentous actin reorganization in response to treatments with microtubule inhibiting agents. Immunoblotting experiments revealed that exposure of glioblastoma cells to epothilone B had no effect on $\alpha$-actinin 4 protein levels (Fig. 7).
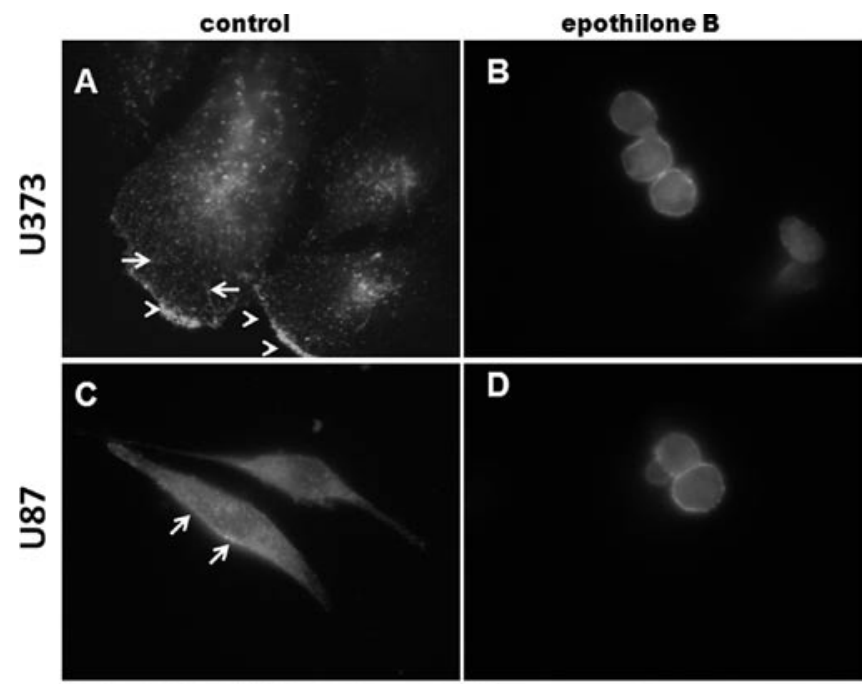

D
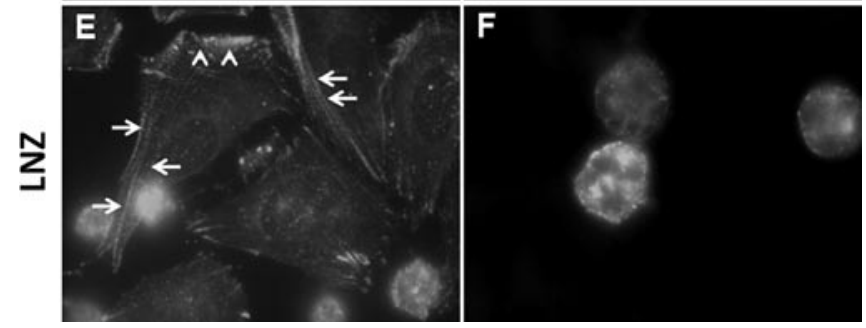

Figure 6. Redistribution of the actin-binding protein, $\alpha$-actinin 4 . Vehicle (DMSO) treated cells (A, C, E, left panel); glioblastoma cells treated with epothilone B (25 nM) for $24 \mathrm{~h}$ (B, D, F, right panel). Arrows, stress fibers: arrow heads, leading edge. Displayed is a representative experiment of four independent experiments showing similar results. Original magnification, $\mathrm{x} 1000$.

Furthermore, because epothilone B primarily targets microtubules and we observed epothilone B induced changes in actin containing structures (leading edge, stress fibers) and the actin-binding protein, $\alpha$-actinin 4 ; we assessed if epothilone $\mathrm{B}$ invoked changes on the Microtubule actin cross linking factor protein (MACF), a spectraplakin cytoskeletal protein family member that cross links microfilaments and microtubules (24-29). Immunolabeling experiments showed a diffuse cytoplasmic and nuclear localization of MACF in vehicle control treated cells (Fig. 8A, C and E). In contrast MACF staining was reduced in the nucleus of U373 cells and not detected in the cytoplasm of these cells treated with epothilone B (Fig. 8B). Consistent with our observation in epothilone B treated U373 cells, the cytoplasm of LNZ cells treated with epothilone B also lacked cytoplasmic labeling

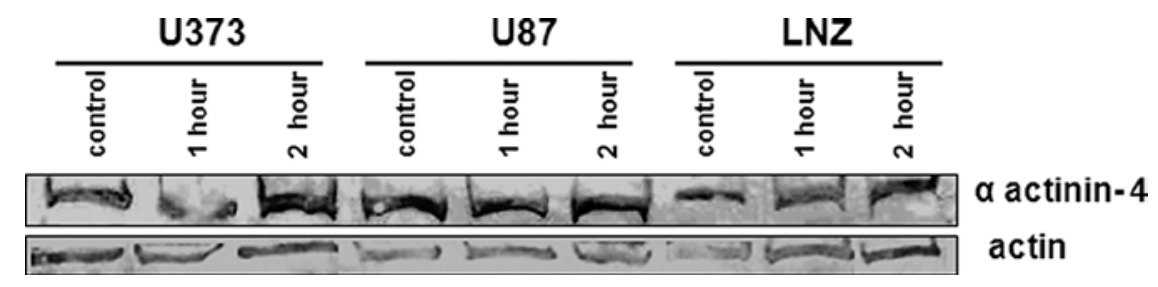

Figure 7. Evaluation of $\alpha$-actinin 4 protein levels in glioblastoma cells treated with epothilone B (25 nM). Displayed is a representative experiment of four independent experiments showing similar results. 


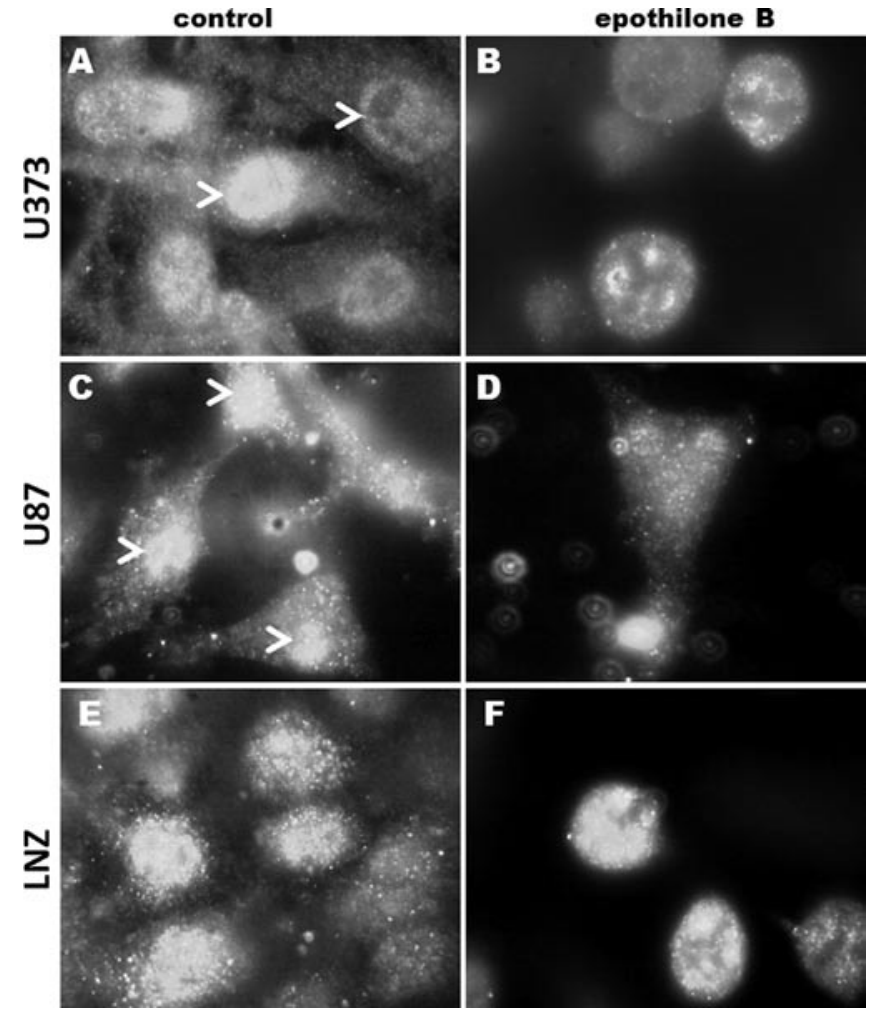

Figure 8. Microtubule actin cross-linking factor (MACF) protein localization in glioblastoma (U373, U87, LNZ) cells. Vehicle control treated cells (A, C and E, left panel); epothilone B treated cells (B, D and F, right panel). Arrow heads, nuclear localization of MACF. Displayed is a representative experiment of at least three independent experiments showing similar result Original magnification, $\mathrm{x} 1000$.

of MACF (Fig. 8F), while epothilone B diminished levels of nuclear MACF in U87 glioblastoma cells (Fig. 8D).

\section{Discussion}

As with most malignancies, clinical glioblastomas are comprised of a mass of proliferating cells as well as migratory cells that subsequently invade normal brain tissue. In this context, experimental studies performed by Giese et al (30) examined the response of human glioma cells to extracellular matrix proteins using BrdU labeling and a microliter cell migration assay, and showed that cell density or non-permissive substrates inhibit cell motility and favor a more proliferative phenotype. Paralleling these findings, McDonough et al (31) demonstrated that human glioma cells selected for their ability to migrate on a glioma-derived extracellular matrix underwent arrest, but displayed an enhanced migration rate as compared to parental cells. Collectively these studies demonstrated that glioma cell proliferation and migration are independent cellular processes that occur in this tumor and suggest that differential cellular programs are a contributing factor to the clinical resistance of this neoplasm.

We investigated here the utility of the anti-mitotic agent, epothilone B, in inhibiting glioma cell motility. Epothilones have been shown by us and others to negatively affect the reproductive capacity of glioma, colon, lung, and prostate cancer cells $(10,32)$; however, its effect on cell motility has been less well characterized. Although several experimental investigations have demonstrated that classic microtubule inhibiting agents impair cell motility, the use of these agents are limited clinically because they are substrates for the drug efflux pump P-glycoprotein, unlike epothilones. We showed here that clinically relevant concentrations of epothilone $\mathrm{B}$ inhibited the motility of the most aggressive type of glioma, glioblastoma-multiforme. Impairment of glioblastoma cell motility by epothilone B observed in the present study was due in part to reduced glioblastoma cell adhesion and collapse of the leading edge and stress fibers, as indicated by redistribution of $\alpha$-actinin 4 , an actin-binding protein localized to these cellular structures with an established role in the motility of metastatic breast, colorectal, brain, and ovarian cancers (17-21). Taken together epothilone B induced aberrations in the leading edge and stress fibers of glioblastoma cells seen here, irrespective of changes in $\alpha$-actinin 4 protein levels, suggests that the observed effects on glioblastoma cell motility are a consequence of interfering with actin dynamics and actin containing structures and domains. The significance of the effects of epothilone $\mathrm{B}$ on $\alpha$-actinin 4 are underscored by results from a recent study where we demonstrated that $\alpha$-actinin 4 displayed significantly higher protein levels in high grade (III-IV) glioblastomas as compared to normal brain tissue (16). Furthermore, our results are consistent with studies undertaken by Hayot et al (33) and Bijman et al (22), who also demonstrated that microtubule targeting agents invoked reduced endothelial cell motility as a consequence of actin-reorganization.

It should also be mentioned that morphological changes and redistribution of $\alpha$-actinin 4 in glioblastoma cells observed in this study post-epothilone B exposure are not likely due to cell death. This is supported in part by dose response data in this study that displayed minimal toxicity of epothilone B treated glioblastoma cells, particularly U87 cells which did not show any toxic effects in response to epothilone B treatment. Furthermore, the notion that structural domain changes seen here are glioblastoma cells undergoing cell death in response to epothilone B is not supported by our previous investigation where we demonstrated in time course studies that showed epothilone B inhibited glioblastoma cell reproductive capacity of LNZ glioblastoma cells as consequence of invoking growth arrest, while a transient growth arrest followed by proliferative recovery was observed in U87 glioblastoma cells post-epothilone B exposure (10). Taken together, the ability of epothilone B to inhibit glioblastoma cell motility but minimal effect on glioblastoma cell proliferation, at least in U87 cells, further supports the premise that these tumors have endogenous divergent cellular programs and behaviors that can be attributed in part to their heterogeneous backgrounds that contribute to the clinical resistance of these cancers and dictate their responses to therapy.

As discussed above data presented here provide evidence that epothilone B antagonizes glioblastoma cell motility as a result of disrupting structures (leading edge, stress fibers) and structural proteins ( $\alpha$-actinin 4 ) important in cell motility, our data also indicate that epothilone B disrupts the cross-talk relationship between microtubules and microfilaments during this cellular program that is mediated by the cytoskeleton cross-linking spectraplakin protein, MACF. A role for MACF 
in cell migration has been recently established in studies conducted in endodermal and epithelium cells, by Kodama et al (24) and Wu et al (25), respectively, that showed cells lacking MACF compromised cell movement, supporting in part our notion in the present study that diminished MACF cytoplasmic labeling in epothilone B treated glioblastoma cells contributes to the impairment of glioblastoma cell motility. Collectively, our data suggest that the underlying mechanism of epothilone B inhibited glioblastoma cell motility observed here is due to a breakdown of microtubules and microfilaments as a result of $\alpha$-actinin 4 and the MACF spectraplakin protein to maintain the structural integrity of the cellular filamentous network.

The utility of epothilone B and its analogues are particularly promising agents for the treatment of glioblastomas because they are not substrates for the drug efflux protein, P-glycoprotein, which is expressed at high levels in the bloodbrain barrier (34-36). Furthermore, this compound appears capable of antagonizing diverse cellular programs (proliferation, cell motility) that comprise the glioblastoma tumor mass and contribute to its therapeutic resistance. Results described in this study together with our previous findings (10) that epothilone B impairs the reproductive capacity of glioblastoma cells provide preclinical evidence that this microtubule targeting agent has potential clinical applications for the treatment of glioblastomas.

\section{Acknowledgements}

Support for this research for the purchase of supplies and reagents were provided in part by a Research Initiative for Scientific Enhancement training grant (2R25GM06671405A1) from the National Institutes of Health (USA), the Ernest E. Just Endowed Professorship (Grambling State University), and a Louisiana Board of Regents grant LEQSF(2009-10)ENH-UG-20.

\section{References}

1. Giese A, Bjerkvig R, Berens ME, et al: Cost of migration: invasion of malignant gliomas and implications for treatment. J Clin Oncol 21: 1624-1636, 2003.

2. Hadfield JA, Ducki S, Hirst N, et al: Tubulin and microtubules as targets for anticancer drugs. Prog Cell Cycle Res 5: 309-325, 2003 .

3. Mollinedo F and Gajate C: Microtubules, microtubule-interfering agents and apoptosis. Apoptosis 8: 413-450, 2003.

4. Honore S, Kamath K, Braguer D, et al: Synergistic suppression of microtubule dynamics by discodermolide and paclitaxel in non-small cell lung carcinoma cells. Cancer Res 64: 4957-4964, 2004.

5. Pellegrini F and Budman DR: Review: tubulin function, action of antitubulin drugs, and new drug development. Cancer Invest 23: $264-273,2005$.

6. Zhou J and Giannakakou P: Targeting microtubules for cancer chemotherapy. Curr Med Chem Anticancer Agents 5: 65-71, 2005.

7. Dumontet C and Sikic BI: Mechanisms of action of and resistance to antitubulin agents: microtubule dynamics, drug transport, and cell death. J Clin Oncol 17: 1061-1070, 1999.

8. Dumontet C: Mechanisms of action and resistance to tubulinbinding agents. Expert Opin Investig Drugs 9: 779-788, 2000.

9. Fojo AT and Menefee M: Microtubule targeting agents: basic mechanisms of multidrug resistance (MDR). Semin Oncol 32 (Suppl. 7): S3-S8, 2005

10. Quick Q: Epothilone B induces glioblastoma cell death via survivin down-regulation. Exp Oncol 30: 195-201, 2008.
11. Westerlund A, Hujanen E, Höyhtyä M, et al: Ovarian cancer cell invasion is inhibited by paclitaxel. Clin Exp Metastasis 15: 318-328, 1997.

12. Belotti D, Rieppi M, Nicoletti MI, et al: Paclitaxel (Taxol(R)) inhibits motility of paclitaxel-resistant human ovarian carcinoma cells. Clin Cancer Res 2: 1725-1730, 1996.

13. Tonn JC, Haugland HK, Saraste J, et al: Differential effects of vincristine and phenytoin on the proliferation, migration, and invasion of human glioma cell lines. J Neurosurg 82: 1035-1043, 1995.

14. Ogasawara M, Matsubara T and Suzuki H: Screening of natural compounds for inhibitory activity on colon cancer cell migration. Biol Pharm Bull 24: 720-723, 2001.

15. Pan Y, Jing R, Pitre A, Williams BJ and Skalli O: Intermediate filament protein synemin contributes to the migratory properties of astrocytoma cells by influencing the dynamics of the actin cytoskeleton. FASEB J 22: 3196-3206, 2008.

16. Quick Q and Skalli O: Alpha-actinin 1 and alpha-actinin 4 . contrasting roles in the survival, motility, and Rho A signaling of astrocytoma cells. Exp Cell Res 316: 1137-1147, 2010.

17. Honda K, Yamada T, Endo R, et al: Actinin-4, a novel actinbundling protein associated with cell motility and cancer invasion. J Cell Biol 140: 1383-1393, 1998.

18. Honda K, Yamada T, Hayashida Y, et al: Actinin-4 increases cell motility and promotes lymph node metastasis of colorectal cancer. Gastroenterology 128: 51-62, 2005.

19. Koizumi T, Nakatsuji H, Fukawa T, et al: The role of actinin-4 in bladder cancer invasion. Urol 75: 357-364, 2010.

20. Sen S, Dong M and Kumar S: Isoform-specific contributions of alpha-actinin to glioma cell mechanobiology. PLoS One 4: e8427, 1-9, 2009.

21. Barbolina MV, Adley BP, Kelly DL, et al: Motility-related actinin alpha-4 is associated with advanced and metastatic ovarian carcinoma. Lab Invest 88: 602-614, 2008.

22. Bijman MN, van Nieuw Amerongen GP, Laurens N, et al: Microtubule-targeting agents inhibit angiogenesis at subtoxic concentrations, a process associated with inhibition of Rac1 and Cdc42 activity and changes in the endothelial cytoskeleton. Mol Cancer Ther 5: 2348-2357, 2006.

23. Rosenblum MD and Shivers RR: 'Rings' of F-actin form around the nucleus in cultured human MCF7 adenocarcinoma cells upon exposure to both taxol and taxotere. Comp Biochem Physiol C Toxicol Pharmacol 125: 121-131, 2000.

24. Kodama A, Karakesisoglou I, Wong E, et al: ACF7: an essential integrator of microtubule dynamics. Cell 115: 343-354, 2003.

25. Wu X, Kodama A and Fuchs E: ACF7 regulates cytoskeletalfocal adhesion dynamics and migration and has ATPase activity. Cell 135: 137-148, 2008

26. Bernier G, Pool M and Kilcup M: Acf7 (MACF) is an actin and microtubule linker protein whose expression predominates in neural, muscle, and lung development. Dev Dyn 219: 216-225, 2000.

27. Röper K, Gregory SL, Brown NH, et al: The 'spectraplakins': cytoskeletal giants with characteristics of both spectrin and plakin families. J Cell Sci 115: 4215-4225, 2002.

28. Sonnenberg A and Liem RK: Plakins in development and disease. Exp Cell Res 313: 2189-2203, 2007.

29. Etienne-Manneville S: Actin and microtubules in cell motility: which one is in control? Traffic 5: 470-477, 2004.

30. Giese A, Loo MA, Tran N, et al: Dichotomy of astrocytoma migration and proliferation. Int J Cancer 67: 275-282, 1996.

31. McDonough W, Tran N, Giese A, et al: Altered gene expression in human astrocytoma cells selected for migration: I. Thromboxane synthase. J Neuropathol Exp Neurol 57: 449-455, 1998.

32. Cheng KL, Bradley T and Budman DR: Novel microtubuletargeting agents - the epothilones. Biologics 2: 789-811, 2008.

33. Hayot C, Farinelle S, De Decker R, et al: In vitro pharmacological characterizations of the anti-angiogenic and anti-tumor cell migration properties mediated by microtubule-affecting drugs, with special emphasis on the organization of the actin cytoskeleton. Int J Oncol 21: 417-425, 2002.

34. Begley DJ: ABC transporters and the blood-brain barrier. Curr Pharm Des 10: 1295-1312, 2004.

35. Löscher W and Potschka H: Blood-brain barrier active efflux transporters: ATP-binding cassette gene family. NeuroRx 2: 86-98, 2005.

36. Scherrmann JM: Expression and function of multidrug resistance transporters at the blood-brain barriers. Expert Opin Drug Metab Toxicol 1: 233-246, 2005. 